\title{
Evapotranspiração e produção do melão Gália irrigado com água de diferentes salinidades e adubação nitrogenada ${ }^{1}$
}

\author{
Talyana K. de Melo $^{2}$, José F. de Medeiros ${ }^{3}$, José Espínola Sobrinho ${ }^{3}$, \\ Vladimir B. Figueirêdo ${ }^{3}$, Vagna da C. Pereira ${ }^{4} \&$ Marcos de S. Campos ${ }^{4}$
}

\begin{abstract}
RESU M 0
Este trabalho objetivou determinar a evapotranspiração e a produção do melão Gália irrigado com água de diferentes níveis de salinidade e doses de nitrogênio. Para tanto, conduziu-se um experimento no município de Mossoró, RN, no delineamento em blocos ao acaso, em parcelas subdivididas $5 \times 3$, com quatro repetições. $O \mathrm{~s}$ tratamentos foram constituídos dos níveis de salinidade: $S_{1}=0,65 ; S_{2}=1,65$;

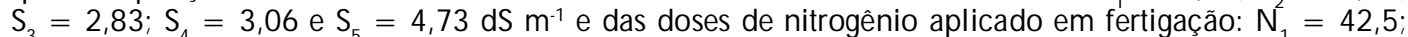
$\mathrm{N}_{2}=85,0$ e $\mathrm{N}_{3}=127,5 \mathrm{~kg} \mathrm{ha}{ }^{-1}$. A evapotranspiração da cultura foi medida por lisímetros de pesagem, que representava uma área ocupada pelas plantas de $3,2 \mathrm{~m}^{2}$ e se encontravam instalados nos níveis de salinidade $\mathrm{S}_{1}$ e $\mathrm{S}_{5}$ em duas repetições. O bservou-se que a evapotranspiração da cultura diminuiu entre a água de irrigação $S_{1}$ e $S_{5}$, sendo o valor total encontrado durante o ciclo de 204,5 e 172,4 mm, respectivamente. Houve perda nas produtividades comercial e total de, respectivamente, 12 , 19 e $15 \%$ e de 10, 16 e 13\%, para os níveis de nitrogênio $N_{1}, N_{2}$ e $N_{3}$ nesta ordem, por aumento unitário da salinidade da água de irrigação (CEa), tomando-se como referểncia a produção obtida com a água de menor salinidade.
\end{abstract}

Palavras-chave: Cucumis melo L., água salina, lisímetro de pesagem, manejo da irrigação

\section{Evapotranspiration and yield of melon Galia irrigated with water of different salinity and nitrogen fertilization}

\begin{abstract}
A B STRACT
This study aimed to determine the evapotranspiration and the yield of melon Galia irrigated with water of different salinity levels and nitrogen. Therefore, an experiment was carried out in Mossoró, RN, northeastern Brazil, in a completely randomized block design, with split-plots $(5 \times 3)$ and four replications. The treatments were the salinity levels $S_{1}=0,65 ; S_{2}=1,65 ; S_{3}=2,83 ; S_{4}=3,06$ e $_{5}=4,73 \mathrm{dS} \mathrm{m}^{-1}$ (assigned to the plots) and nitrogen: $\mathrm{N}_{1}=42,5 ; \mathrm{N}_{2}=85,0 \mathrm{e} \mathrm{N}_{3}=127,5 \mathrm{~kg} \mathrm{ha}^{-1}$ (applied through fertigation to the subplots). The evapotranspiration of the crop was measured with weighing lysimeters, which occupied an area of $3,2 \mathrm{~m}^{2}$, located in two replications of $S_{1}$ and $S_{5}$. The crop evapotranspiration decreased in the range of the salinity levels $S_{1}$ to $S_{5}$ and totalized 204,5 and $172,4 \mathrm{~mm}$, respectively. There were losses on marketable and total productivity, respectively, 12,19 and $15 \%$ and 10,16 and $13 \%$ for nitrogen levels $N_{1}, N_{2}$ and $N_{3}$, per unit increase in salinity of irrigation water $\left(\mathrm{EC}_{w}\right)$, taking as reference the yield with water of lowest $\mathrm{EC}_{\mathrm{w}}$.
\end{abstract}

Key words: Cucumis melo L., saline water, weighing lysimeter, irrigation management

\footnotetext{
${ }^{1}$ Trabalho extraído da Dissertação de Mestrado da primeira autora, UFERSA, Mossoró, RN

2 Eng. Agrônoma, mestre em Irrigação e D renagem, Bolsista DTI, D CAT/UFERSA, Av. Francisco M ota 572, Bairro Costa e Silva. CEP 59625-900, Mossoró, RN. Fone (84) 3317-8340. E-mail: talyanakadja@hotmail.com

DCAT/U FERSA, M ossoró, RN. Fone (84) 3317-8340,E-mail: jfmedeir@ufersa.edu.br, jespinola@ufersa.edu.br, vladimir@ufersa.edu.br

Graduando em Agronomia. Bolsista PICI/U FERSA, Mossoró, RN
} 


\section{INTRODUÇÃO}

A agricultura irrigada depende da quantidade e da qualidade da água. Dentre as características que determinam a qualidade da água para a irrigação, a concentração de sais solúveis ou salinidade é fator limitante ao desenvolvimento da maioria das culturas (Bernardo et al., 2008).

Embora a maioria das fontes de água na região produtora de melão seja de boa qualidade existem, em Mossoró, águas de qualidade inferior em quantidade significativa que, no entanto, podem ser utilizadas na irrigação, tanto de forma isolada como misturada ou alternada com as de boa qualidade. Em tais casos, a utilização da água salobra fica condicionada à tolerância das culturas à salinidade e ao manejo da irrigação (Oliveira \& Maia, 1998).

As diferentes espécies e cultivares de plantas reagem diferentemente à salinidade, isto é, cada espécie de planta ou cultivar tolera até determinada salinidade, sem reduzir seu rendimento potencial (salinidade limiar - SL), a partir da qual passa a diminuir a produtividade à medida em que se incrementa a salinidade do solo (Ayers \& Westcot, 1999). Além disso, a salinidade reduz a disponibilidade de água para as plantas pelo efeito osmótico causando, consequentemente, uma absorção menor de nutrientes, quando aplicados via água de irrigação.

Segundo Bhella \& Wilcox (1989), dentre os nutrientes o nitrogênio é o mais absorvido pelo melão e sua deficiência ou excesso pode afetar diretamente a produtividade da cultura e a qualidade dos frutos.

A relação do nitrogênio com a salinidade nas plantas cultivadas é bastante complexa. Um grande número de estudos indica que a absorção ou acumulação de $\mathrm{N}$ na parte aérea pode ser reduzida pela salinidade enquanto outros trabalhos apresentam o oposto ou nenhum efeito.

Kafkafi (1984) sugere, como medida para reduzir os efeitos da salinidade, o aumento da dose de nitrogênio aplicada melhorando, assim, a qualidade dos frutos. Segundo este autor, existem evidências de competição na absorção entre nitrato e cloreto, de modo que um aumento na concentração de nitrato na zona radicular pode inibir maior absorção de cloreto pela planta.

Investigações relativas à tolerância a salinidade do meloeiro, apesar do grande interesse envolvido, são escassas para alguns tipos e cultivares atualmente exploradas na região; entretanto, para uma estratégia racional de manejo de irrigação faz-se necessário o conhecimento dos efeitos dos sais da água de irrigação sobre o solo e a planta em diferentes estágios de desenvolvimento; referidos dados permitem estabelecer critérios de maior exposição da planta ao meio adverso e à necessidade de uma boa condução cultural, orientando racionalmente a irrigação (Medeiros et al., 2008).

Vários pesquisadores têm tentado desenvolver uma função de produção para as culturas em relação à água de irrigação salina (Letey et al., 1985; Letey \& Dinar, 1986; Bresler, 1987). Esses modelos combinam relações entre rendimentos e evapotranspiração, entre rendimento e salinidade na zona radicular e entre salinidade na zona radicular e a fração de lixiviação.
Para Curi \& Campelo Júnior (2001), as pesquisas sobre evapotranspiração fornecem informações da quantidade de água consumida pelas plantas através de dados para o manejo da água e para o dimensionamento dos sistemas de irrigação, tendo a FAO, nas últimas décadas, recomendado reiteradamente a realização de pesquisas locais para determinar a demanda hídrica das culturas, sobretudo para estimar e medir a evapotranspiração, haja vista que a escolha de determinado método de evapotranspiração deve ser precedida por uma calibração local.

As medidas da evapotranspiração podem ser feitas utilizando-se lisímetros de pesagem acoplados a sistemas modernos de aquisição de dados, porém alguns problemas operacionais dificultam sua instalação em larga escala, tornando-os padrão comparativo para teste de equações e modelos de estimativas.

Allen et al. (1991) apresentaram extensa revisão de diversos tipos de lisímetros destacando-se, como mais precisos, os de pesagem, que determinam diretamente a evapotranspiração pela variação da massa de um volume de solo vegetado e confinado por paredes impermeáveis, durante um intervalo de tempo.

Com base no exposto o presente trabalho teve como objetivo determinar o efeito da salinidade da água de irrigação e de doses de nitrogênio aplicadas via fertigação na produção da cultura do melão Gália e o efeito da salinidade na sua evapotranspiração e determinar o fator de redução da produção em relação à evapotranspiração.

\section{Material e MÉTODOS}

O experimento foi conduzido na Fazenda Experimental Rafael Fernandes, localizada no distrito de Alagoinha (5 $5^{\circ} 03^{\prime} 37^{\prime \prime} \mathrm{S} ; 37^{\circ}$ 23' 50" W e altitude de $72 \mathrm{~m}$ ), pertencente à Universidade Federal Rural do Semiárido - UFERSA, distante $20 \mathrm{~km}$ da sede municipal de Mossoró, RN. O solo da área experimental é classificado como Argissolo Vermelho-Amarelo, fase caatinga hiperxerófila e relevo plano.

De acordo com a classificação climática de Köppen, o clima de Mossoró é do grupo BSwh', isto é, clima seco, muito quente e com estação chuvosa no verão atrasando-se para o outono, apresentando temperatura média de $27,4{ }^{\circ} \mathrm{C}$, precipitação pluviométrica anual muito irregular, com média de $673,9 \mathrm{~mm}$ e umidade relativa do ar de 68,9\% (Carmo Filho \& Oliveira, 1995).

Os dados climáticos médios verificados no período do experimento, foram: temperatura do ar; umidade relativa do ar; radiação solar global e velocidade do vento iguais a $27,2{ }^{\circ} \mathrm{C}$; $63,1 \% ; 23,3 \mathrm{MJ} \mathrm{m}^{-2} \mathrm{~d}^{-1} \mathrm{e} 2,95 \mathrm{~m} \mathrm{~s}^{-1}$, respectivamente. Durante todo o ciclo da cultura verificou-se a ocorrência de apenas um evento de precipitação, que foi aos 34 dias após transplantio (DAT) de 1,0 mm.

Adotou-se o delineamento experimental em blocos ao acaso, em esquema de parcelas subdivididas 5 x 3, com quatro repetições. Os tratamentos foram constituídos de cinco níveis de salinidade da água de irrigação $\left(\mathrm{S}_{1}=0,65 ; \mathrm{S}_{2}=1,65 ; \mathrm{S}_{3}=\right.$ 2,$83 ; \mathrm{S}_{4}=3,06 \mathrm{e}_{5}=4,73 \mathrm{dS} \mathrm{m}^{-1}$, valores médios medidos durante o ciclo da cultura) e três níveis de nitrogênio aplicados via 
fertigação nas subparcelas experimentais $\left(\mathrm{N}_{1}=42,5 ; \mathrm{N}_{2}=85,0\right.$ $\left.\mathrm{e}_{3}=127,5 \mathrm{~kg} \mathrm{ha}^{-1}\right)$.

As parcelas experimentais se compuseram de três fileiras de plantas de $6,8 \mathrm{~m}$ de comprimento cada uma, espaçadas $2,0 \mathrm{~m}$, sendo considerada área útil da parcela para avaliação da produção, a fileira central, da qual foi subtraída uma planta de cada extremidade.

A água de menor salinidade $\left(\mathrm{S}_{1}\right)$ foi proveniente do poço artesiano profundo e a água de maior salinidade $\left(\mathrm{S}_{5}\right)$ foi produzida previamente, em tanque de $5.000 \mathrm{~L}$, com a mistura dos sais $\mathrm{NaCl}, \mathrm{CaCl} \cdot 2 \mathrm{H}_{2} \mathrm{O}$ e $\mathrm{MgSO}_{4} \cdot 6 \mathrm{H}_{2} \mathrm{O}$, de modo que a relação catiônica $\mathrm{Na}: \mathrm{Ca}: \mathrm{Mg}$ fosse de 7:2:1, em mol $\mathrm{L}^{-1}$. Os outros três níveis de salinidade da água foram obtidos da mistura dessas duas águas e monitorados diariamente, através de condutivímetro portátil com compensação de temperatura, a partir da água coletada durante cada evento de irrigação, em dois gotejadores para cada mistura.

Os níveis de nitrogênio foram aplicados via fertigação, cuja dose padrão foi de $85,0 \mathrm{~kg} \mathrm{ha}^{-1}(100 \%)$, valor aproximado ao usualmente utilizado em cultivos comerciais, pelos produtores da região.

Os três níveis de nitrogênio foram produzidos com o arranjo das linhas de gotejadores, da seguinte forma: em todo o experimento se instalaram duas linhas de gotejadores por fileira de planta, em que a uma dessas duas linhas era fornecida a adubação nitrogenada e os níveis $\mathrm{N}_{1}(50 \%)$ e $\mathrm{N}_{3}(150 \%)$ de cada parcela foram obtidos com a utilização de gotejadores que tinham a mesma vazão e eram espaçados $0,6 \mathrm{~m}$ e 0,2 m, respectivamente, o que forneceu vazões diferentes por metro linear; consequentemente, o nível de adubação era diferente em cada parcela; já a outra linha de gotejadores foi instalada apenas para compensar o volume de água aplicado em cada parcela, isto é, onde se tinha gotejadores espaçados $0,2 \mathrm{~m}$ na linha do nitrogênio se tinha, também, gotejadores espaçados $0,6 \mathrm{~m}$ na outra linha dentro da parcela e vice-versa, enquanto para o nível $\mathrm{N}_{2}$ as duas linhas apresentaram gotejadores de mesma vazão $\left(1,3 \mathrm{~L} \mathrm{~h}^{-1}\right)$ que eram espaçados $0,3 \mathrm{~m}$ proporcionando, então, uma vazão igual por metro linear e adubação nitrogenada média nesta parcela, sistema que proporcionou lâminas de irrigação idênticas e níveis de $\mathrm{N}$ variáveis, conforme cada tratamento.

O plantio da cultura ocorreu no dia 29 de outubro de 2008, utilizando-se mudas de 12 dias após semeadura, adquiridas de um fornecedor comercial de produção de mudas. Utilizou-se o melão tipo Gália híbrido Néctar, pertencente ao grupo botânico Cucumis melo L. var. Cantalupensis Naud., em espaçamento entre plantas de $0,4 \mathrm{~m}$. A cultura foi conduzida com o uso do mulch (cobertura de solo com filme de polietileno preto-branco com a face branca voltada para cima).

Realizou-se o manejo da irrigação com base na estimativa da evapotranspiração máxima da cultura (ETm) conforme o método proposto pela FAO 56 (Allen et al., 2006) acrescida de uma fração de lixiviação de 0,09 . A lâmina bruta total de irrigação aplicada durante o ciclo da cultura foi de $327,4 \mathrm{~mm}$.

Visando à determinação da ETc nos diversos estádios de desenvolvimento da planta, utilizaram-se quatro lisímetros de pesagem, idênticos, instalados nas parcelas de menor $\left(\mathrm{S}_{1}\right) \mathrm{e}$ maior $\left(\mathrm{S}_{5}\right)$ salinidade com a aplicação da dose de nitrogênio $\mathrm{N}_{2}$, nos blocos experimentais B1 e B2, denominados lisímetros S1B1, S5B1, S1B2 e S5B2, respectivamente; já para análise da ETc entre esses dois níveis de salinidade $\left(\mathrm{S}_{1}\right.$ e $\left.\mathrm{S}_{5}\right)$, consideraramse repetições as semanas dentro de cada fase: I - 0-21 DAT (inicial); II - 22-35 DAT (desenvolvimento); III - 36-49 DAT (intermediária) e IV - 50-61 DAT (final), mais os dois lisímetros por tratamento. Adotou-se o delineamento inteiramente casualizado em parcela sudividida, sendo as subparcelas as fases.

Os lisímetros possuíam dimensões de 1,5 x 1,5 m de área e 1,0 m de profundidade útil (dimensões internas), constituídos de chapa de aço de $3 \mathrm{~mm}$, com saída para drenagem localizada no fundo da caixa, a qual era utilizada quando havia formação de lençol freático.

Esta caixa interna de aço (lisímetro) estava instalada em cima de uma balança eletrônica de precisão que, por sua vez, se encontrava assentada em uma laje de concreto com espessura de $15 \mathrm{~cm}$; externa a essa caixa estava instalada uma outra, constituída do mesmo material da primeira, também assentada na mesma laje de concreto, espaçada da caixa interna aproximadamente $5,0 \mathrm{~cm}$, com dimensões de 1,6 x 1,6 m.

A balança eletrônica utilizada foi da marca Açores, modelo específico, cuja capacidade de peso é de $5.000 \mathrm{~kg}$; esta balança possui uma barra de pesagem (braço de apoio), do qual se ligava o elemento sensível (célula de carga) transferindo o peso do conjunto lisimétrico à célula de carga com redução na proporção de 1:50 nos lisímetros do bloco 1; já para os lisímetros do bloco 2 foi utilizado um contra-peso ligado ao braço, o que permitiu aumentar a sensibilidade da célula de carga.

A irrigação nos lisímetros foi feita através de um sistema independente, instalado próximo a cada lisímetro, utilizandose espaguetes para distribuição de água às plantas, técnica esta utilizada para se ter um controle maior no volume de água que entrava no sistema lisimétrico.

Para efeito de cálculo da evapotranspiração, os dados lisimétricos foram tomados a partir da diferença de massa do conjunto solo-caixa, no início do dia $(0$ h) e a massa obtida no final do dia $(24 \mathrm{~h})$, em que as leituras foram analisadas diariamente, para que ocorrências de chuva, irrigação ou drenagem do volume de solo controlado, fossem identificadas e desconsideradas do cálculo da ETc, conforme metodologia proposta por Silva et al. (2005).

Uma vez realizado este procedimento diário obtiveram-se a massa pela conversão do sinal elétrico, utilizando-se a equação de calibração, e a lâmina evapotranspirada obtida pela relação entre a massa e a área ocupada pelas quatro plantas existentes no lisímetro $(1,6 \times 2,0 \mathrm{~m})$, de vez que a cultura foi explorada com o uso de cobertura plástica não havendo, portanto, evaporação de água do solo mas apenas transpiração das plantas.

Realizaram-se duas colheitas, aos 54 e 61 DAT (dias após transplantio), quando então todos os frutos de cada parcela foram pesados e classificados em frutos comerciáveis ou refugo.

Avaliaram-se os seguintes componentes de produção: massa média dos frutos comerciais (MMC) e massa média dos frutos totais (MMT), expressos em g; número médio de frutos comerciais (NFC) e número médio de frutos totais (NFT); para a produtividade foram tomados os dados de produtividade 
comercial (PRC) e produtividade total (PRT), expressos em $\mathrm{Mg} \mathrm{ha}^{-1}$.

Os dados foram submetidos a análise de variância e as médias do fator nitrogênio comparadas através do teste Tukey a 0,05 de probabilidade e os efeitos do fator salinidade avaliados por análise de regressão, utilizando-se o desdobramento dos graus de liberdade dos polinômios ortogonais. Utilizou-se, para tanto, o software livre SISVAR, versão 5.0. Para fins de análise de variância consideraram-se os dados de apenas três blocos da área experimental: 1, 2 e 4 uma vez que houve problemas de stand no bloco 3 , motivados por questões alheias aos tratamentos.

Realizou-se, também, uma análise de produtividade da cultura relacionando-se a evapotranspiração obtida com os níveis de maior $\left(\mathrm{S}_{5}\right)$ e menor $\left(\mathrm{S}_{1}\right)$ salinidade e quando irrigado com a dose $\mathrm{N}_{2}$ utilizando-se, para tal fim, o fator de resposta Ky, proposto por Doorenbos \& Kassam (1994) dado pela Eq. 1.

$$
\mathrm{Ky}^{\prime}=\frac{\left(1-\frac{\mathrm{Ya}}{\mathrm{Ym}}\right)}{\left(1-\frac{\mathrm{ETR}}{\mathrm{ETc}}\right)}
$$

em que:

Ky'- fator de resposta da produção à ETc da cultura, adimensional

Ya - produção da cultura obtida sob condições de stress salino, $\mathrm{Mg} \mathrm{ha}^{-1}$

Ym - produção máxima obtida sem ocorrência de stress, $\mathrm{Mg} \mathrm{ha}{ }^{-1}$

ETR - evapotranspiração da cultura obtida com a salinidade $\mathrm{S}_{5}, \mathrm{~mm}$

ETc-evapotranspiração da cultura obtida com a salinidade $\mathrm{S}_{1}, \mathrm{~mm}$

Para determinação do coeficiente de stress por salinidade, Ks, que descreve o efeito do stress hídrico/salino na evapotranspiração da cultura, utilizou-se a Eq. 2 (Allen et al., 2006).

$$
\mathrm{Ks}=1-\frac{1}{\mathrm{Ky}}\left(1-\frac{\mathrm{Ya}}{\mathrm{Ym}}\right)
$$

em que:

Ya - produção da cultura obtida sob condições de maior salinidade $\left(\mathrm{S}_{5}\right), \mathrm{Mg} \mathrm{ha}^{-1}$

Ym - produção máxima obtida sob condições de baixa salinidade $\left(\mathrm{S}_{1}\right), \mathrm{Mg} \mathrm{ha}^{-1}$

Ky - fator de resposta da produção ao déficit hídrico, adimensional

Desta forma, a evapotranspiração da cultura ajustada para condições de salinidade (ETcaj), foi obtida pela Eq. 3.

$$
\mathrm{ETcaj}=\mathrm{ETcSl}_{*} \mathrm{Ks}
$$

em que:

ETcaj - evapotranspiração da cultura sob condições de maior salinidade, $\mathrm{mm}$

$\mathrm{ETcS}_{1}$ - evapotranspiração da cultura sob condições de baixa salinidade, $\mathrm{mm}$

Ks - coeficiente de stress salino, adimensional

\section{Resultados E DisCussão}

\section{Evapotranspiração da cultura}

Os valores de evapotranspiração da cultura (ETc) obtidos pelos lisímetros nos níveis de salinidade $\mathrm{S}_{1}(\mathrm{ETcS} 1)$ e $\mathrm{S}_{5}$ (ETcS5) estão apresentados na Figura 1. Verifica-se que na primeira fase não houve diferença significativa entre os valores de ETc para as duas salinidades, principalmente na primeira semana após transplante, uma vez que a água de irrigação aplicada foi a mesma $\left(\mathrm{CE}=0,65 \mathrm{dS} \mathrm{m}^{-1}\right)$ para os dois tratamentos, até $5 \mathrm{DAT}$.

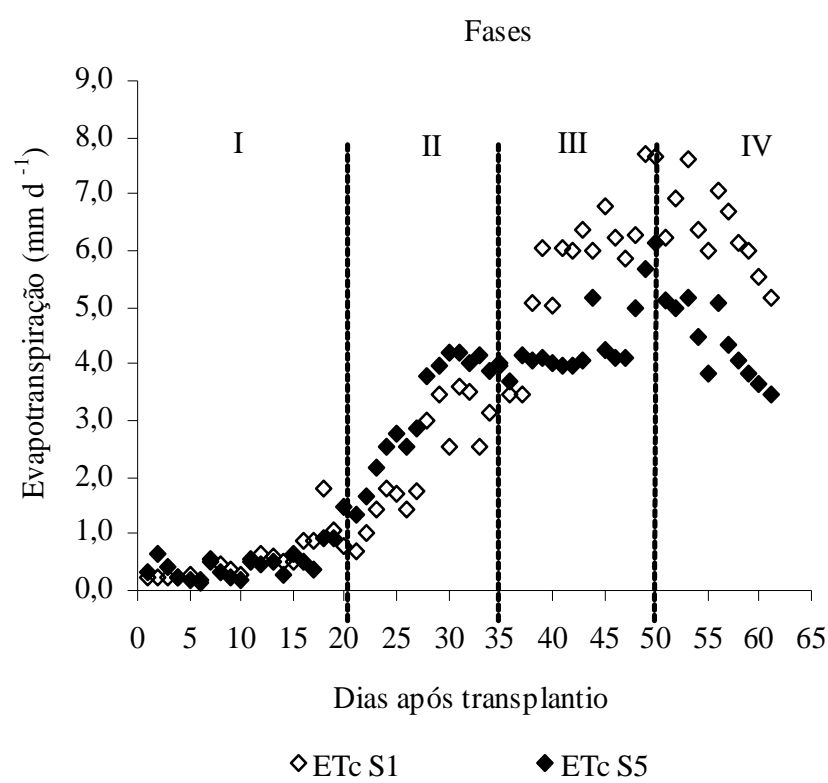

Figura 1. Evapotranspiração da cultura do mel oeiro no nível de salinidade $\mathrm{S}_{1}$ (ETCS1) e no nível $\mathrm{S}_{5}$ (ETCS5)

A partir dos 20 DAT os valores de ETcS5 tenderam a ser superiores à $\mathrm{ETcS} 1$; no entanto, não apresentaram efeito significativo a nível de 5\% de probabilidade (Tabela 1); já nas fases intermediária e final a ETcS1 foi sempre maior que a ETcS5 com médias, durante o período, de 6,47 e 4,62 $\mathrm{mm} \mathrm{d}^{-1}$ para os tratamentos $\mathrm{S}_{1}$ e $\mathrm{S}_{5}$ na fase III, respectivamente, e de 6,08 e 4,09 $\mathrm{mm} \mathrm{d}^{-1}$, na fase IV.

Tabela 1. Valores médios para os dados de evapotranspiração da cultura referentes à interação salinidade versus fases

\begin{tabular}{ccccc}
\hline \multirow{2}{*}{ Salinidade } & \multicolumn{5}{c}{ Fases } \\
\cline { 2 - 5 } & I & II & III & IV \\
$\mathrm{S}_{1}$ & $0,56 \mathrm{a} *$ & $3,34 \mathrm{a}$ & $6,65 \mathrm{a}$ & $5,91 \mathrm{a}$ \\
$\mathrm{S}_{5}$ & $0,53 \mathrm{a}$ & $3,56 \mathrm{a}$ & $4,80 \mathrm{~b}$ & $3,87 \mathrm{~b}$ \\
\hline
\end{tabular}

* Médias seguidas da mesma letra na coluna não diferem entre si pelo teste de Tukey, a 0,05 de probabilidade 
Esses resultados demonstram que o efeito da salinidade sobre a evapotranspiração é mais intenso nas fases de maior desenvolvimento das plantas e evidenciam, ainda, que a resposta das plantas ao estresse salino é variável de acordo com a fase de desenvolvimento da cultura, corroborando com os resultados obtidos por Farias et al. (2003) com a cultura do meloeiro.

A evapotranspiração da cultura do transplantio até 61 DAT, determinada a partir dos lisímetros, foi de 204,5 e 172,4 mm para otratamento $S_{1}$ e $S_{5}$, respectivamente, correspondendo a uma diferença de mais de $30 \mathrm{~mm}$ entre os dois tratamentos no consumo de água durante todo o ciclo da cultura, constatação que implica no fato de que o consumo de água diminuiu com a irrigação com água de salinidade mais elevada.

Outros estudos têm constatado redução na evapotranspiração em resposta à salinidade para diferentes culturas de interesse agronômico (Medeiros et al., 2005; Figueirêdo et al., 2009). De acordo com Lima (1997), os efeitos da acumulação excessiva dos sais solúveis sobre as plantas podem ser causados pelas dificuldades de absorção de água, pela toxicidade de íons específicos e pela interferência dos sais nos processos fisiológicos (efeitos indiretos), reduzindo o crescimento das plantas e, em contrapartida, a evapotranspiração.

\section{Produção e componentes de produção}

Através da análise de variância (Tabela 2), verifica-se efeito significativo dos níveis de salinidade da água de irrigação sobre todas as variáveis de produção estudadas; já para as doses de nitrogênio não houve efeito significativo apenas para massa média dos frutos (comerciais e totais); observou-se, ainda, interação significativa salinidade versus nitrogênio para PRC, PRT, NFT e MMT, indicando haver dependência entre os efeitos dos fatores para essas características.

$\mathrm{Na}$ literatura consultada observam-se inúmeros trabalhos relatando o efeito da salinidade sobre os diversos componentes de produção do meloeiro e a própria produtividade da cultura (Barros et al., 2003; Farias et al., 2003; Porto Filho et al., 2006; Figueirêdo, 2008; Medeiros et al., 2008; Gurgel et al., 2010). Com relação ao efeito dos níveis de nitrogênio também são registradas respostas significativas deste fator isolado sobre as variáveis de produção do meloeiro (Coelho et al., 2001; Sousa et al., 2005; Pinto et al., 2006). Verifica-se, portanto, coerência entre os resultados aqui apresentados e na literatura disponível.

Os efeitos da interação salinidade versus nitrogênio para as variáveis NFT, MMT, PRC e PRT, são mostrados na Figura 2. Para NFT verificou-se redução significativa e linear com o aumento da salinidade da água de irrigação nas plantas fertilizadas com o nível de nitrogênio padrão (100\%), não sendo possível ajustar nenhum modelo polinomial para os demais níveis de nitrogênio (Figura 2A). A MMT foi afetada significativamente pela salinidade observando-se, ainda, que o efeito foi variável com o nível de $\mathrm{N}$, de forma que, para os níveis 50 e $100 \%$, foi ajustado ao modelo cúbico enquanto com o nível de $150 \%$ a equação ajustada foi linear decrescente (Figura 2B).

Em referência às PRC e PRT, apresentaram comportamento semelhante quando da utilização das três doses de nitrogênio, ou seja, em todos os casos os modelos de melhor ajuste foram linear e decrescente, observando-se que a diminuição mais acentuada na produtividade (tanto comercial como total) foi constatada na dose de nitrogênio padrão (100\%), apresentando decréscimo de 4,20 e 5,25 $\mathrm{Mg} \mathrm{ha}^{-1}$ para PRC e PRT, respectivamente, por aumento unitário da salinidade da água de irrigação (Figura 2C e 2D).

Para PRC e PRT, tal como para todos os componentes de produção avaliados (NFC, NFT, MMC e MMT), tiveram seus valores máximos alcançados no nível de nitrogênio $\mathrm{N}_{2}(100 \%)$. Comparando-se as equações de regressão quando se utilizou a dose de nitrogênio $\mathrm{N}_{2}$, para os componentes de produção: número de frutos comercial e total e massa média dos frutos comerciais e totais (Figura 2A e 2B e Figura 3), observaram-se decréscimos lineares por aumento unitário da salinidade da água de irrigação (CEa) de 15, 12, 7 e 6\%, respectivamente, resultando em perdas totais de 60, 47, 29 e 26\%, nas plantas irrigadas com água de salinidade de $4,73 \mathrm{dS} \mathrm{m}^{-1}$ comparandose com os valores obtidos com a salinidade de $0,65 \mathrm{dS} \mathrm{m}^{-1}$. Constata-se, desta forma, que os rendimentos foram mais afetados pelo número de frutos do que pela sua massa média.

Comportamento semelhante foi encontrado por Barros et al. (2003), em trabalho realizado com a cultura do meloeiro, na mesma região em que foi desenvolvido o presente experimento. Este comportamento pode ser atribuído ao elevado índice de abortamento em decorrência de algum fator fisiológico e/ou

Tabela 2. Resumo da análise de variância para os dados dos componentes da produção e produtividade do meloeiro (PRC - Produtividade Comercial; N FC - Número de Frutos Comerciais; M MC - M assa M édia dos Frutos Comerciais; PRT - Produtividade Total; NFT - N úmero de Frutos Totais; M MT - M assa M édia dos Frutos Totais) irrigado com águas de diferentes salinidades

\begin{tabular}{lccccccc}
\hline \multirow{2}{*}{ Fonte de variação } & \multirow{2}{*}{ G.L. } & \multicolumn{6}{c}{ Quadrados médios } \\
\cline { 3 - 8 } & & PRC & NFC & MMC & PRT & NFT & MMT \\
Bloco & 2 & $57,59^{*}$ & $120,09^{* *}$ & $0,00221^{\text {n.s. }}$ & $41,67^{\text {n.s. }}$ & $36,47^{\text {n.s. }}$ & $0,00822^{\text {n.s. }}$ \\
Salinidade (S) & 4 & $148,50^{* *}$ & $186,81^{* *}$ & $0,04715^{* *}$ & $239,79^{* *}$ & $220,64^{*}$ & $0,07278^{* *}$ \\
Resíduo I & 8 & 10,60 & 17,23 & 0,00426 & 14,48 & 59,41 & 0,00267 \\
Nitrogênio (N) & 2 & $73,57^{* *}$ & $112,29^{* *}$ & $0,00314^{\text {n.s. }}$ & $119,66^{* *}$ & $240,80^{* *}$ & $0,00422^{\text {n.s. }}$ \\
Interação (S x N) & 8 & $19,31^{*}$ & $22,59^{\text {n.s. }}$ & $0,00551^{\text {n.s. }}$ & $26,45^{* *}$ & $55,08^{*}$ & $0,00509^{*}$ \\
Resíduo II & 20 & 5,55 & 13,83 & 0,00256 & 7,36 & 21,99 & 0,00179 \\
Total & 44 & & & & & & \\
\hline $\mathrm{CV}_{1}(\%)$ & & 28,84 & 25,14 & 9,77 & 21,08 & 23,31 & 9,63 \\
$\mathrm{CV}_{2}(\%)$ & 20,88 & 22,53 & 7,57 & 15,02 & 14,18 & 7,88 \\
\hline
\end{tabular}

** significativo a 0,01 de probabilidade; * significativo a 0,05 de probabilidade; ${ }^{\text {n.s. }}$ não significativo, pelo teste $\mathrm{F}$ 


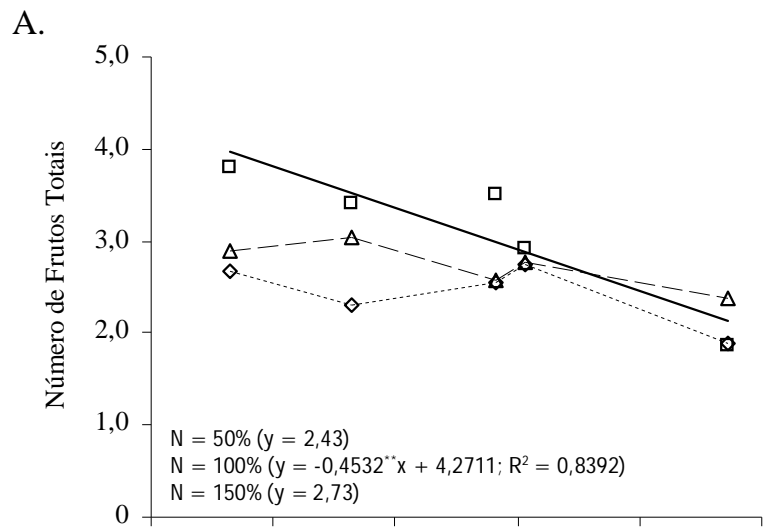

B.

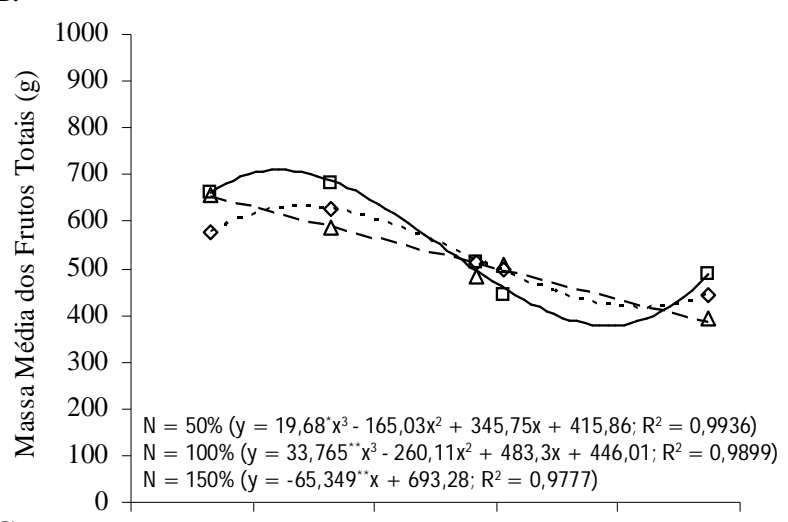

C.

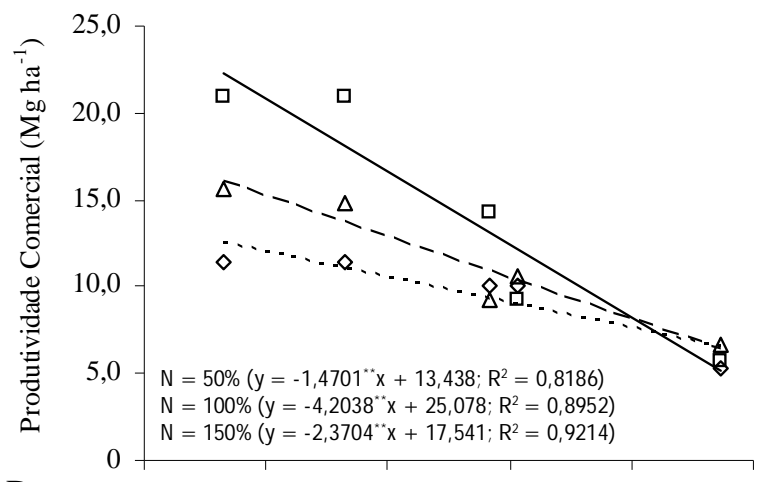

D.

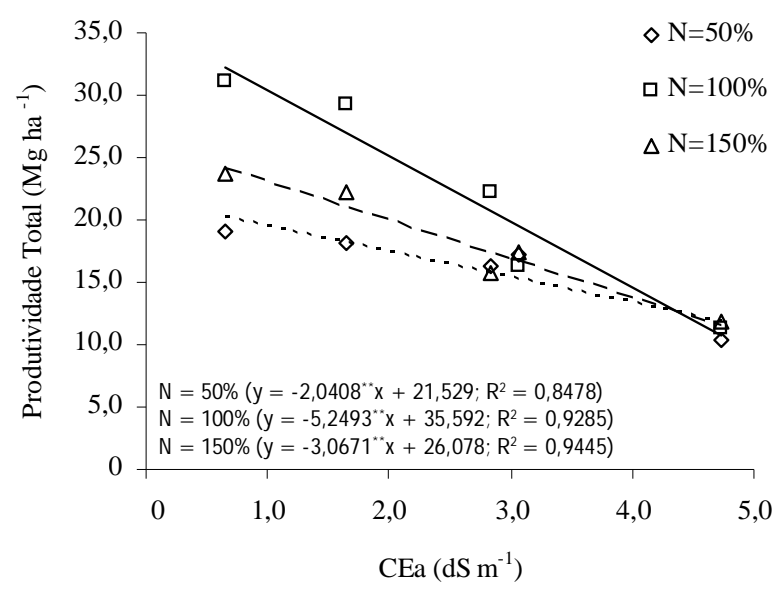

Figura 2. Número de Frutos Totais (A), Massa Média dos Frutos Totais (B), Produtividade Comercial (C) e Produtividade Total (D) em função da salinidade da água de irrigação (CEa) e para diferentes doses de $\mathrm{N}$ aplicadas em fertigação bioquímico, devido à elevada concentração de sais, o que parece normal pela limitação fisiológica das plantas quando submetidas a diferentes níveis de salinidade; assim, com a redução do número de frutos foi possível o desenvolvimento dos frutos remanescentes justificando, a partir de então, o menor efeito da salinidade sobre a massa média dos frutos.

Houve perdas nas PRC e PRT, nos níveis $\mathrm{N}_{1}, \mathrm{~N}_{2}$ e $\mathrm{N}_{3}$, na ordem de aproximadamente 48,77 e $61 \%$ para PRC e de 41,67 e $52 \%$ para PRT, na maior salinidade $\left(4,73 \mathrm{dS} \mathrm{m}^{-1}\right)$ em comparação com a menor salinidade $\left(0,65 \mathrm{dS} \mathrm{m}^{-1}\right)$, correspondendo a um decréscimo de 12, 19 e 15\% para PRC e de 10,16 e 13\% para PRT por aumento unitário da salinidade da água de irrigação (CEa).

Constata-se, desta forma, que nas condições em que se realizou o experimento a produtividade do meloeiro foi influenciada negativamente pelo incremento da salinidade na água de irrigação, numa proporção muito maior do que na evapotranspiração da cultura.

As análises de regressão mostraram haver ajustes significativos do NFC e MMC em função da salinidade da água de irrigação. O comportamento dessas variáveis seguiu modelo linear decrescente indicando que a redução do NFC e MMC acompanhou o incremento da salinidade da água de irrigação (Figura 3).

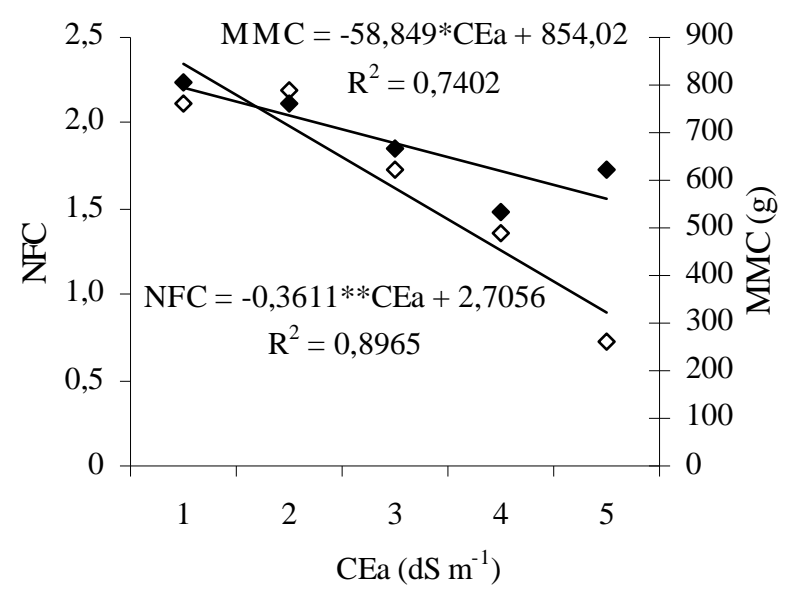

$\diamond \mathrm{NFC} \quad \mathrm{MMC}$

Figura 3. Número de frutos comerciais (NFC) e massa média dos frutos comerciais (M MC) do meloeiro irrigado com água de diferentes salinidades

Tendo em vista que o rendimento máximo ocorreu para a menor salinidade estudada $\left(\mathrm{S}_{1}\right)$ estabeleceu-se, como salinidade limiar (SL) da cultura, aquela que permite produzir rendimento relativo mínimo de 90\%, conforme sugerem Ayers \& Westcot (1999). De posse dos valores de PRC e PRT obtidos para cada nível de salinidade, encontrou-se um valor de SL de 1,48 e 1,46 $\mathrm{dS} \mathrm{m}^{-1}$ para produtividade comercial e total, respectivamente, bem abaixo de 2,4 dS m ${ }^{-1}$, relatado por Ayers \& Westcot (1999) para um rendimento de $90 \%$ do melão cantaloupe; salienta-se, no entanto, que, conforme os autores, a SL é determinada, para o meloeiro, com relação à salinidade do solo (CEes), enquanto no presente trabalho foi avaliada a salinidade da água de irrigação (CEa). Os valores de SL determinados neste trabalho 
são próximos aos encontrados por Figueirêdo (2008) em condições semelhantes às que foram verificadas neste trabalho, para o melão tipo Orange flesh, cultivar County.

Referidos resultados mostram a importância da definição da salinidade máxima em que a produtividade da cultura não é afetada pela salinidade (SL) da água de irrigação adequada para maximizar a produção e, sobretudo, para minimizar os custos de produção do meloeiro.

$\mathrm{O}$ incremento da dose de $\mathrm{N}$ aplicada acima da dose recomendada quando se utilizou a água de baixa salinidade proporcionou redução no rendimento, o que não foi verificado quando se utilizou água com maiores níveis de sais. Isso pode ser explicado pelo incremento da salinidade do solo, resultando em um aumento no potencial osmótico do solo ocasionado, por sua vez, pela adição de fertilizantes. No entanto, em condição mais salina o efeito do excesso de $\mathrm{N}$ pode ter inibido esse incremento da salinidade gerado pelo excedente de adubo aplicado.

\section{Redução da produção em relação à evapotranspiração}

Encontrou-se um valor de Ks $=0,84$, para o ciclo da cultura, o que representa o efeito da salinidade sobre a evapotranspiração da cultura, com redução de $16 \%$ na ETc (30 $\mathrm{mm})$. Este valor é similar ao valor de Ks de referência contido no manual da FAO 56, quando é dado um valor de $\mathrm{Ks}=0,83$ para uma redução de $17 \%$ na evapotranspiração; estima-se, portanto, que o valor de ETcaj para o ciclo da cultura é somente 0,84 da ETc máxima, ou seja, no nível de salinidade $S_{1}$.

Relacionando a redução da evapotranspiração com as quedas relativas às produções total e comercial, obteve-se o coeficiente Ky', o qual traduz a sensibilidade de produção da cultura ao déficit hídrico, neste caso provocado pela redução da disponibilidade de água para as plantas, resultante do aumento do nível de salinidade da água de irrigação. Através dos valores encontrados verifica-se que o "fator de resposta" Ky' foi maior para a produção comercial $(4,8)$, mostrando grande sensibilidade do meloeiro para fins comerciais, ao stress salino com relação à qualidade dos frutos; já a produção total foi menos sensível, sinalizando um valor menor para Ky' $(4,1)$.

$\mathrm{Na}$ literatura não se encontraram dados referentes ao fator de resposta da produção do meloeiro em função da evapotranspiração da cultura, quando esta é devida ao estresse salino.

Segundo Doorenbos \& Kassam (1994), para culturas nas quais o valor de Ky é desconhecido, pode-se utilizar Ky $=1$ ou admitir um valor correspondente a uma cultura com características similares. Esses autores encontraram, com a cultura da melancia, valores de Ky em torno de 1,1 para condições de estresse hídrico; ainda de acordo com os autores, a melancia é classificada moderadamente tolerante ao déficit hídrico (Ky entre 0,95 e 1,50).

Os altos valores de Ky' para o meloeiro aqui encontrados podem ser explicados pelo nível de evapotranspiração, podendo-se observar uma redução da produção de 77 e $67 \%$ da PRC e PRT, respectivamente, para uma redução de apenas $16 \%$ da evapotranspiração obtida entre os níveis de maior e menor salinidade. Esta redução da produção pode ser atribuída também à redução da disponibilidade de nutrientes, decorrente da oferta de menor quantidade de água à planta, em virtude do estresse salino.

\section{CONCLUSÕES}

1. A evapotranspiração do meloeiro do transplantio até 61 dias após transplantio, foi de $204,5 \mathrm{~mm}$, reduzindo em $16 \%$ quando a salinidade da água de irrigação aumentou de 0,65 para $4,73 \mathrm{dS} \mathrm{m}^{-1}$.

2. O efeito da salinidade na produção do meloeiro se deu mais pela redução do número de frutos do que pela massa média dos mesmos e sua intensidade dependeu da dose de $\mathrm{N}$ aplicada na fertigação.

3. O rendimento comercial e total do meloeiro não foi afetado pelos níveis de salinidade (SL) da água até os valores de 1,48 e $1,46 \mathrm{dS} \mathrm{m}^{-1}$, respectivamente.

4. Houve resposta do melão a doses de $\mathrm{N}$ apenas para os menores níveis de salinidade da água.

5. O fator de resposta da produção (Ky') em relação à evapotranspiração foi de 4,8 e 4,1 para PRC e PRT, respectivamente, e a ETc sob condições de maior salinidade foi $84 \%$ da ETc sob condições de menor salinidade.

\section{Agradecimento}

Ao Conselho Nacional de Desenvolvimento Científico e Tecnológico (CNPq) e a Financiadora de Estudos e Projetos (FINEP) pelo apoio financeiro dado para desenvolover o trabalho.

\section{LITERATURA CITADA}

Allen, R. G.; Pereira, L. S.; Raes, D.; Smith, J. Evapotranspiration del cultivo: guias para la determinación de los requerimientos de agua de los cultivos. Rome: FAO, 2006. 298p. Estudio Riego e Drenaje Paper, 56.

Allen, R. G.; Pruitt, W. O.; Jensen, M. E. Environmental requirements of lisimeters. In: International Symposium On Lysimetry, 1991, Honolulu. Anais... Honolulu: ASCE, 1991. p.170-181.

Ayers, R. S.; Westcot, D. W. A qualidade de água na agricultura. 2.ed. Campina Grande: UFPB, 1999. 153p. FAO. Estudos Irrigação e Drenagem, 29.

Barros, A. D.; Medeiros, J. F. de; Sousa, A. P. Comportamento produtivo do meloeiro submetido a salinidade e frequiência de irrigação. Irriga, v.8, p.44-50, 2003.

Bernardo, S.; Soares, A. A.; Mantovani, E. C. Manual de irrigação. 8.ed. Viçosa: UFV, 2008. 625p.

Bhella, H. S.; Wilcox, G. E. Lime and nitrogen influence soil acidity nutritional status, vegetative growth, and yield of muskmelon. Journal of the American Society for Horticultural Science, v.114, p.606-610, 1989.

Bresler, E. Application of conceptual model to irrigation water requirement and salt tolerance of crops. Journal of the American Society for Soil Science, v.51, p.788-793, 1987. 
Carmo Filho, F.; Oliveira, O. F. Mossoró: Um município do semiárido nordestino, caracterização climática e aspecto florístico. Mossoró: ESAM, 1995. 62p. Coleção Mossoroense, Série B

Coelho, E. F.; Sousa, V. F.; Souza, V. A. B.; Melo, F. B. Efeito de níveis de $\mathrm{N}$ e $\mathrm{K}$ aplicados por gotejamento na cultura do meloeiro (Cucumis melo L.) em solo arenoso. Ciência e Agrotecnologia, v.25, p.23-30, 2001.

Curi, S. , Campelo Júnior, J. H. Necessidades hídricas da cultura do feijoeiro (Phaseolus vulgaris L.) na Baixada Cuiabana. Revista Brasileira de Agrometeorologia, v.9, p.59-65, 2001.

Doorenbos, J.; Kassam, A. H. Efeito da água no rendimento das culturas. Campina Grande: UFPB, 1994. 306p. Estudos FAO: Irrigação e Drenagem, 33

Farias, C. H. A. de; Espínola Sobrinho, J.; Medeiros, J. F. de; Costa, M. C.; Nascimento, L. B.; Silva, M. C. C. Crescimento e desenvolvimento da cultura do melão sob diferentes lâminas de irrigação e salinidade da água. Revista Brasileira de Engenharia Agrícola e Ambiental, v.7, p.445-450, 2003.

Figueirêdo, V. B. Evapotranspiração, crescimento e produção da melancia e melão irrigados com águas de diferentes salinidades. Botucatu: UNESP, 2008. 104p. Tese Doutorado

Figueirêdo, V. B.; Medeiros, J. F. de; Zocoler, J. L.; Espinola Sobrinho, J. Evapotranspiração da cultura da melancia irrigada com água de diferentes salinidades. Engenharia Agrícola, v.29, p.231-240, 2009.

Gurgel, M. T.; Uyeda, C. A.; Gheyi, H. R.; Oliveira, F. H. T.; Fernandes, P. D.; Silva, F. V. Crescimento de meloeiro sob estresse salino e doses de potássio. Revista Brasileira de Engenharia Agrícola e Ambiental, v.14, p.3-10, 2010.

Kafkafi, U. Plant nutrition under saline conditions. In: ShainberG, I.; Shalhevet, K (ed.). Soil salinity under irrigation. Berlin: Springer-Verlag, 1984. p.319-338. Ecological Studies, 51.

Letey J.; Dinar A. Simulated crop-water production functions for several crops when irrigated with saline waters. Hilgardia, v.54, p.1-32, 1986.
Letey, J.; Dinar, A.; Knapp, K. C. Crop-water production function model for saline irrigation waters. Journal of the American Society for Soil Science. v.49, p.1005-1009, 1985.

Lima, L. A. Efeitos de sais no solo e na planta. In: Gheyi, H. R.; Queiroz, J. E.; Medeiros, J. F. de; (ed.). Manejo e controle da salinidade na agricultura irrigada. Campina Grande: UFPB, SBEA, 1997. Cap.4, p.113-127.

Medeiros, F. A. S. B.; Medeiros, J. F. de; Silva, M. C. C.; Alves, L. P.; Souza, T. H.; Levien, S. L. A. Necessidade hídrica do meloeiro irrigado com água de diferentes salinidades e cultivado com ou sem cobertura do solo. Revista Brasileira de Engenharia Agrícola e Ambiental, v.9, p.234-238 , 2005.

Medeiros, J. F. de; Dias, N. da S.; Barros, A. D. de. Manejo da irrigação e tolerância do meloeiro a salinidade da água de irrigação. Revista Brasileira de Ciências Agrárias, v.3, p.242247, 2008.

Oliveira, O.; Maia, C. E. Qualidade físico-química da água para a irrigação em diferentes aquíferos na área sedimentar do Estado do Rio Grande do Norte. Revista Brasileira de Engenharia Agrícola e Ambiental, v.2, p.17 21, 1998.

Pinto, J. M.; Faria, C. M. B.; Feitosa Filho, J. C. Produtividade e qualidade de frutos do meloeiro, em função de nitrogênio e CO aplicados via fertigação. Irriga, v.11, p.198-207, 2006.

Porto Filho, F. Q.; Medeiros, J. F. de; Sousa Neto, E. R.; Gheyi, H. R.; Matos, J. de A. Viabilidade da irrigação do meloeiro com águas salinas em diferentes fases fenológicas. Ciência Rural, v.36, p.453-459, 2006.

Silva, L. D. B.; Folegatti, M. V.; Nova, N. A. V. Evapotranspiração do capim tanzânia obtida pelo método de razão de Bowen e lisímetro de pesagem. Engenharia Agrícola, v.25, p.705-712, 2005.

Sousa, V. F.; Coelho, E. F.; Souza, V. A. B.; Holanda Filho, R. S. F. Efeito de doses de nitrogênio e potássio aplicadas por fertigação no meloeiro. Revista Brasileira de Engenharia Agrícola e Ambiental, v.9, p.210-214, 2005. 